\title{
Kinetic Relevance of Hydrogen Desorption Steps and Virtual Pressures on Catalytic Surfaces during Reactions of Light Alkanes
}

\author{
Sara Y. Yu, Joseph A. Biscardi, ${ }^{\dagger}$ and Enrique Iglesia* \\ Department of Chemical Engineering, University of California at Berkeley, Berkeley, California 94720
}

Received: March 21, 2002; In Final Form: June 24, 2002

\begin{abstract}
Hydrogen removal steps limit alkane dehydrogenation reactions on cation-exchanged H-ZSM5 and cause desorption bottlenecks and the formation of hydrogen-rich reaction intermediates and products. For this reaction, the catalytic surface acts for all kinetic purposes as if it were in equilibrium with a $\mathrm{H}_{2}$ pressure greater than in the prevalent gas phase. The hydrogen chemical potential within adsorbed intermediates is described rigorously by a virtual $\mathrm{H}_{2}$ pressure, defined as that required to achieve the prevalent surface hydrogen content if adsorption-desorption steps were equilibrated. These virtual pressures can be measured from the deuterium content in products formed from $\mathrm{C}_{3} \mathrm{H}_{8} / \mathrm{D}_{2}$ reactants. $\mathrm{H}_{2}$ virtual pressures are high during propane reactions on $\mathrm{H}-\mathrm{ZSM} 5$, because recombinative desorption of hydrogen atoms formed in $\mathrm{C}-\mathrm{H}$ activation steps is slow. $\mathrm{H}_{2}$ virtual pressures decrease as $\mathrm{Zn}$ cations replace protons in $\mathrm{H}-\mathrm{ZSM} 5$, because cations catalyze hydrogen adsorption-desorption steps and provide a kinetic path for communication between $\mathrm{H}_{2}$ in the gas phase and propane-derived reaction intermediates. As a result, the addition of $\mathrm{H}_{2}$ to $\mathrm{C}_{3} \mathrm{H}_{8}$ reactants decreases propane reaction rates and aromatics selectivity on $\mathrm{Zn} / \mathrm{H}-\mathrm{ZSM} 5$, causing it to resemble kinetically $\mathrm{H}-\mathrm{ZSM} 5$. The hydrogen chemical potential on these catalytic surfaces and the hydrogen content within reactive intermediates reflect the rate at which hydrogen is formed in either $\mathrm{C}-\mathrm{H}$ bond activation steps or in the dissociative chemisorption of gas-phase $\mathrm{H}_{2}$. The reaction pathways for species derived from each of these two H-sources are kinetically indistinguishable. Both sources contribute hydrogen atoms or hydrogen-rich species to the prevalent pool of reactive intermediates, the hydrogen content of which determines the rate and selectivity of all surface chemical reactions.
\end{abstract}

\section{Introduction}

Catalytic surfaces and adsorbed intermediates accept and reject hydrogen atoms formed in $\mathrm{C}-\mathrm{H}$ bond activation reactions, the elementary entry step required for the chemical conversion of alkanes. At high temperatures, alkane conversion reactions are often limited by exit steps that desorb fragments formed in relatively fast $\mathrm{C}-\mathrm{H}$ bond activation steps. Previous studies have confirmed the rate-determining nature of hydrogen removal steps and the catalytic role of cations as hydrogen desorption sites during the conversion of alkanes to aromatics on zeolite catalysts. ${ }^{1-5}$ The relative rates of $\mathrm{C}-\mathrm{H}$ bond activation and of various hydrogen disposal pathways (e.g. recombinative hydrogen desorption, hydrogenation and desorption of unsaturated intermediates) determine the hydrogen chemical potential within the pool of adsorbed species prevalent during steady-state catalytic reactions of alkanes.

The nature, concentration, and location of the hydrogen species responsible for this chemical potential and for the resulting hydrogenating properties of such surfaces remain unclear. It appears that this chemical potential influences the hydrogen content in unsaturated adsorbed intermediates, which exist as stable species during hydrocarbon and alcohol reactions on acidic zeolites. ${ }^{6-9}$ These surface intermediates are best described as adsorbed alkoxide species that retain some cationic

* To whom correspondence should be addressed. E-mail: iglesia@cchem. berkeley.edu. Fax: (510) 642-4778.

† Current address: ChevronTexaco Corp., 100 Chevron Way, Richmond, CA 94802. character only in the activated complexes involved in hydrocarbon reactions. ${ }^{10,11}$

UV-visible and infrared spectroscopy studies have detected the presence of unsaturated alkenyl carbenium ions during interactions of propene with $\mathrm{H}-\mathrm{ZSM} 5 .{ }^{12}$ These studies have shown that oligomeric carbenium ions with 6-9 carbon atoms act as persistent carbocations, from which smaller molecules can form via $\beta$-scission pathways. Mono-, di-, and trienyl carbenium ions have also been detected during adsorption of propene on $\mathrm{H}-\mathrm{Na}-\mathrm{Y} .{ }^{12}$ These data suggest that adsorbed species with varying extent of unsaturation and size coexist during reactions of hydrocarbons on zeolitic acids and that their size and hydrogen content influence the nature of their chemical reactions. ${ }^{12}$ The hydrogen chemical potential within this pool of reactive adsorbed species determines the degree of saturation in these intermediates and the products they form. High hydrogen chemical potentials tend to lead to saturated adsorbed species and to hydrogen-rich products, while low hydrogen potentials favor more unsaturated intermediates, which desorb as alkenes or aromatics. Ultimately, very low hydrogen chemical potentials can also lead to nondesorbable species, which can oligomerize and dehydrogenate to form deactivating organic deposits.

\section{Kinetic Treatments of Catalytic Sequences}

Boudart and others ${ }^{1,13-15}$ have provided a theoretical framework for the rigorous treatment of kinetic networks on the basis of nonequilibrium thermodynamic treatments of chemical kinetics (e.g., the Dedonder equation; eq 1). These studies have also 
provided theoretical and experimental evidence for the kinetic relevance of a virtual pressure, which acts as a surrogate for the chemical potential of a given species on reacting surfaces. The De Donder equation (eq 1$)^{16}$ relates the reversibility of an elementary step to its thermodynamic driving force (the reaction affinity).

$$
\frac{v_{i}}{v_{-i}}=\exp \left(\frac{A_{i}}{R T}\right)
$$

The reaction affinity for the $i$ th step, $A_{i}$, defined as $\left(-\Delta G_{i}\right)$, is zero at equilibrium and greater than zero for any reaction proceeding in the forward direction as written. $A_{i}$ is related to the standard reaction affinity available from thermodynamic tables, $A_{i}{ }^{\circ}$, by

$$
A_{i}=A_{i}^{\circ}-R T \ln \prod_{i} f_{j}^{v_{\mathrm{j}, \mathrm{i}}}
$$

where $f_{j}$ is the fugacity of component $j$ and $v_{j, i}$ is the stoichiometric coefficient of component $j$ in reaction step $i$. A quasi-equilibrated step proceeds at almost identical rates in the forward and reverse directions, and its affinity is nearly zero $\left(A_{i}=0\right)$; therefore,

$$
\prod_{i}\left(f_{j}^{v_{\mathrm{j}, \mathrm{i}}}\right)_{\mathrm{eq}}=\exp \left(A_{i}^{\circ} / R T\right)
$$

Irreversible steps $\left(v_{i} \gg v_{-i}\right)$ have a large and positive affinity $\left(A_{i}>0\right)$, which accounts for the affinity of the overall chemical reaction when a single step is kinetically relevant (ratedetermining). This causes eq 2 to become

$$
\prod_{i}\left(f_{j}^{v_{\mathrm{j}, \mathrm{i}}}\right)_{\mathrm{ss}}<\exp \left(A_{i}^{\circ} / R T\right)
$$

for all nonequilibrated elementary steps. Dividing eq 3 by eq 4 leads to

$$
\frac{\prod_{i}\left(f_{j}^{v_{\mathrm{j}, \mathrm{i}}}\right)_{\mathrm{eq}}}{\prod_{i}\left(f_{j}^{v_{\mathrm{j}, \mathrm{i}}}\right)_{\mathrm{ss}}}>1
$$

If the remaining steps are quasi-equilibrated, the products of the rate-determining step have nearly identical steady-state and equilibrium fugacities, and eq 5 becomes

$$
\frac{\prod_{i}\left(f_{j}^{\left|v_{\mathrm{j}, \mathrm{i}}\right|}\right)_{\mathrm{ss}}}{\prod_{i}\left(f_{j}^{\left|v_{\mathrm{j}, \mathrm{i}}\right|}\right)_{\mathrm{eq}}}>1
$$

where $f_{j}$ is only the fugacity of the reactants involved in the $i$ th step. From this inequality, it is clear that steady-state fugacities for the reactants involved in a rate-determining step must exceed those that would correspond to thermodynamic equilibrium with the gas-phase products of this reaction step.

Equation 6 predicts that the surface fugacity of hydrogen during steady-state propane dehydrogenation will exceed that expected from equilibrium with the $\mathrm{H}_{2}$ present in the gas phase

$$
f_{\left(\mathrm{H}_{2}\right)_{\mathrm{gas}}}<f_{\left(\mathrm{H}_{2}\right)_{\mathrm{v}}}
$$

unless desorption steps are quasi-equilibrated.
When the gas phase is ideal eq 7 becomes

$$
P_{\left(\mathrm{H}_{2}\right)_{\text {gas }}}<P_{\left(\mathrm{H}_{2}\right)_{\mathrm{v}}}
$$

$P_{\left(\mathrm{H}_{2}\right)_{\mathrm{v}}}$ or $\left(\mathrm{H}_{2}\right)_{\mathrm{v}}$ is the "virtual" pressure of hydrogen, defined as the gas-phase $\mathrm{H}_{2}$ pressure required to achieve the hydrogen surface concentration $\left(\left[\mathrm{H}^{*}\right]_{\mathrm{ss}}\right)$ prevalent during the steady-state catalytic reaction, if hydrogen-adsorption steps were actually equilibrated. ${ }^{15}$ For dehydrogenation reactions, this virtual pressure always exceeds the gas-phase $\mathrm{H}_{2}$ pressure, except when desorption is quasi-equilibrated, in which case the two values become equal. Hydrogen virtual pressures on catalytic surfaces become higher as hydrogen removal steps become increasingly irreversible. As they do, surfaces become effective sources of hydrogen for hydrogenation reactions, and they use adsorbed hydrocarbon species as hydrogen "reservoirs" with varying hydrogen content and chemical potential. In turn, these species participate in "hydrogen transfer" reactions that form increasingly saturated intermediates and products as the hydrogen virtual pressure increases.

The concept of a virtual pressure (or fugacity), as a surrogate description of the chemical potential of adsorbed species, was first described for $\mathrm{NH}_{3}$ decomposition reactions on $\mathrm{Fe}$, for which the recombinative desorption of $\mathrm{N}$ adatoms was irreversible and rate-determining. The formation of $\mathrm{Fe}$ nitrides during $\mathrm{NH}_{3}$ decomposition on Fe reflects the high virtual $\mathrm{N}_{2}$ pressure caused by this desorption bottleneck. Formation of iron nitride, $\mathrm{Fe}_{4} \mathrm{~N}$, from $\mathrm{Fe}$ at $673 \mathrm{~K}$ requires very high $\mathrm{N}_{2}$ pressures $\left(1.0 \times 10^{5}\right.$ $\mathrm{kPa})$; yet, an equimolar mixture of $\mathrm{NH}_{3}$ and $\mathrm{H}_{2}(100 \mathrm{kPa}$ total $)$ led to the rapid formation of iron nitride, as a result of a steadystate chemical potential of adsorbed nitrogen corresponding to that of $100 \mathrm{MPa} \mathrm{N}_{2}$ in the gas phase. ${ }^{15,17,18}$ Auger electron spectroscopic studies on $\mathrm{W}^{19}$ and $\mathrm{Mo}^{13}$ foils confirmed that $\mathrm{N}^{*}$ surface coverages during steady-state $\mathrm{NH}_{3}$ decomposition are much higher than those expected from equilibrium with the prevalent $\mathrm{N}_{2}$ pressure. The inequality $\left(\mathrm{N}^{*}\right)_{\mathrm{ss}}>\left(\mathrm{N}^{*}\right)$ must be satisfied for recombinative desorption to show a positive affinity, as required for every elementary step in a reaction sequence.

Alkane dehydrocyclization reactions lead to high hydrogen chemical potentials on $\mathrm{Te} / \mathrm{NaX}$ catalysts. ${ }^{13} \mathrm{C}$ isotopic tracer studies showed that primary $n$-heptane dehydrogenation steps were quasi-equilibrated. Yet, gas phase 1 -heptene/ $n$-heptane molar ratios were significantly lower than predicted from equilibrium at the prevalent $\mathrm{H}_{2}$ pressure. In effect, this step attained equilibrium on a surface with a hydrogen chemical potential greater than in the contacting gas phase. The resulting hydrogen chemical potential in adsorbed species, expressed rigorously as a virtual pressure or fugacity, provides the kinetically and thermodynamically relevant measure of hydrogen availability and reactivity for all elementary steps involving such species in surface-catalyzed reactions.

The conversion of alkanes to aromatics, and the activation of light alkanes in general, are considered difficult because their endothermic nature and the strong $\mathrm{C}-\mathrm{H}$ bonds in alkanes require high temperatures for practical rates and high equilibrium conversions. Here, we show that the rate, selectivity, and stability of cation-exchanged H-ZSM5 alkane conversion catalysts are influenced by the removal of hydrogen as either $\mathrm{H}_{2}$ or as alkanes formed via hydrogenation of alkenes formed in acid-catalyzed $\beta$-scission reactions. The kinetic relevance of hydrogen removal steps, which operate far from equilibrium during these alkane reactions, leads to surface hydrogen chemical potentials much higher than in the gas phase. A rigorous method for assessing this chemical potential and the "hydrogenating" tendency of such surfaces involves their 
description in terms of a virtual $\mathrm{H}_{2}$ pressure, which provides a rigorous measure of the chemical potential of hydrogen in the pool of reactive surface intermediates prevalent during steadystate catalysis. These virtual $\mathrm{H}_{2}$ pressures can be measured via isotopic tracer experiments using alkane $-\mathrm{D}_{2}$ mixtures, which exploit operative oligomerization-cracking cycles in order to distribute hydrogen isotopes statistically among all reaction products. These measurements have also shown that cations such as $\mathrm{Zn}, \mathrm{Co}$, and others increase alkane conversion rates by increasing the rate of removal of hydrogen as $\mathrm{H}_{2}$ and, in this manner, decreasing the hydrogen chemical potential in the pool of reactive intermediates.

\section{Experimental Methods}

Catalyst Synthesis and Characterization. H-ZSM5 was prepared by aqueous ion exchange of Na-ZSM5 (Zeochem, $\mathrm{Si} / \mathrm{Al}=14.5$ ) with an ammonium nitrate solution. $\mathrm{Zn} / \mathrm{H}-\mathrm{ZSM} 5$ materials were prepared by ion exchange of $\mathrm{H}-\mathrm{ZSM} 5$ with a solution of $\mathrm{Zn}\left(\mathrm{NO}_{3}\right)_{2}$. Additional synthesis details have been reported previously. ${ }^{20-22}$

${ }^{27} \mathrm{Al}$ NMR and infrared spectroscopy did not detect any extraframework $\mathrm{Al}$ in these samples. ${ }^{21,23}$ Infrared and $\mathrm{D}_{2-} \mathrm{OH}$ isotopic exchange studies showed only traces of silanol groups. ${ }^{20,21}$ Atomic emission spectroscopy (Galbraith Laboratories, Inc.) detected trace amounts of residual $\mathrm{Na}$ in $\mathrm{H}-\mathrm{ZSM} 5$ (0.14 wt $\% ; \mathrm{Na} / \mathrm{Al}=0.064)$. The three $\mathrm{Zn} / \mathrm{H}-\mathrm{ZSM} 5$ samples contained 0.62 wt $\% \mathrm{Zn}(\mathrm{Zn} / \mathrm{Al}=0.10), 1.07$ wt $\% \mathrm{Zn}(\mathrm{Zn} / \mathrm{Al}=0.16)$, and 1.30 wt $\% \mathrm{Zn}(\mathrm{Zn} / \mathrm{Al}=0.19)$.

Catalytic Reactor Studies. Reaction rates and selectivities were measured at $773 \mathrm{~K}$ in a tubular packed-bed reactor using $\mathrm{C}_{3} \mathrm{H}_{8}(20 \mathrm{kPa}) / \mathrm{He}(180 \mathrm{kPa})$ reactants. The effects of $\mathrm{H}_{2}$ on reaction rates, selectivity, and deactivation were examined on $\mathrm{H}-\mathrm{ZSM} 5$ and $\mathrm{Zn} / \mathrm{H}-\mathrm{ZSM} 5$ at $773 \mathrm{~K}$ using $\mathrm{C}_{3} \mathrm{H}_{8}(20 \mathrm{kPa}) / \mathrm{H}_{2}$ $(0-100 \mathrm{kPa})$ mixtures with $\mathrm{He}$ at a total pressure of $200 \mathrm{kPa}$. Propane (Praxair, $>99.5 \%$ ) was purified using $\mathrm{O}_{2} / \mathrm{H}_{2} \mathrm{O}$ traps (Matheson). $\mathrm{H}_{2}$ (Praxair, UHP) and $\mathrm{He}$ (Praxair, UHP) were purified using $\mathrm{O}_{2}$ (Matheson) and $13 \mathrm{X}$ sieve traps. Residence times were changed by varying the flow rate of the reactant mixture. Product selectivities were measured as a function of residence time (and propane conversion) in order to discern primary and secondary reaction pathways. The deactivation behavior of the catalysts was studied at constant space velocity.

The outlet stream composition was measured by gas chromatography (Hewlett-Packard 6890) using a capillary column (Hewlett-Packard, HP-1 methylsilicone column, 50 m, $0.32 \mathrm{~mm}$ diameter, $1.05 \mu \mathrm{m}$ film thickness) and flame ionization detection. Propane conversion rates are reported as molar propane conversion rates/Al mol. Selectivities are reported on a carbon basis, as the percentage of carbon in the converted propane that appears as a given product. The $\mathrm{H}_{2}$ selectivity was calculated from the difference in the hydrogen contents in reactants and products; it is reported as the percentage of the $\mathrm{H}$-atoms in the converted propane appearing as $\mathrm{H}_{2}$.

Hydrogen Virtual Pressure Estimates. The virtual pressure of hydrogen was measured from the deuterium fraction in $\mathrm{C}_{3+}$ products formed from $\mathrm{C}_{3} \mathrm{H}_{8} / \mathrm{D}_{2}$ reactant mixtures. Some of the results presented were obtained using a recirculating reactor and $26.6 \mathrm{kPa} \mathrm{C}_{3} \mathrm{H}_{8}$ and $6.7 \mathrm{kPa} \mathrm{D}_{2} ;^{3}$ the remaining data were obtained in the tubular plug-flow reactor described above using $20 \mathrm{kPa} \mathrm{C}_{3} \mathrm{H}_{8}$ and $10 \mathrm{kPa} \mathrm{D}$ and several space velocities. These two types of reactors provide equivalent information.

The deuterium content in $\mathrm{C}_{2}+$ products was measured by gas chromatography using electron-impact mass spectrometry (Hewlett-Packard 5972, mass selective detector) and matrix techniques that correct for ion fragmentation. ${ }^{24}$ Deuterium contents were measured as a function of residence time and extrapolated to zero reactant conversion, for which the gas-phase retains the isotopic purity of the starting reactants.

The H/D atomic ratio in $\mathrm{C}_{3} \mathrm{H}_{8} / \mathrm{D}_{2}$ reaction products (extrapolated to zero conversion) was used to estimate hydrogen virtual pressures, because it provides a measure of the relative amounts of $\mathrm{H}$ (from $\mathrm{C}_{3} \mathrm{H}_{8}$ ) and $\mathrm{D}$ (from $\mathrm{D}_{2}$ ) within the pool of adsorbed surface intermediates leading to reaction products. The $\mathrm{H}$-content in the pool of surface intermediates (from $\mathrm{C}_{3} \mathrm{H}_{8}$ ) is related directly to a virtual pressure of $\mathrm{H}_{2}$ in the same way as the $\mathrm{D}$-content in the adsorbed intermediates is related to the $\mathrm{D}_{2}$ pressure in the gas phase. If $\mathrm{H}_{2}$ dissociates and provides two mobile $\mathrm{H}$-atoms, the square of the ratio of $\mathrm{H}$ and $\mathrm{D}$ atoms in the pool of adsorbed intermediates would be related to the ratio of $\mathrm{H}_{2}$ and $\mathrm{D}_{2}$ (eq 9).

If $\mathrm{H}_{2}$ dissociates and one $\mathrm{H}$-atom is mobile and the other remains immobile at the dissociation site, the ratio of $\mathrm{H}$ and $\mathrm{D}$ atoms in the pool of adsorbed intermediates would be related to the ratio of $\mathrm{H}_{2}$ and $\mathrm{D}_{2}$ (eq 10).

$$
\begin{aligned}
& \frac{\left[\mathrm{H}^{*}\right]^{2}}{\left[\mathrm{D}^{*}\right]^{2}}=\frac{\left(\mathrm{H}_{2}\right)_{\mathrm{v}}}{\left(\mathrm{D}_{2}\right)_{\mathrm{g}}} \\
& \frac{\left[\mathrm{H}^{*}\right]}{\left[\mathrm{D}^{*}\right]}=\frac{\left(\mathrm{H}_{2}\right)_{\mathrm{v}}}{\left(\mathrm{D}_{2}\right)_{\mathrm{g}}}
\end{aligned}
$$

The discussion and results presented below provide evidence for the latter mechanism for hydrogen adsorption-desorption during propane reactions on cation-modified $\mathrm{H}-\mathrm{ZSM}$ 5.

\section{Results and Discussion}

Alkane Dehydrocyclization on $\mathrm{H}-\mathrm{ZSM} 5$ and $\mathrm{Zn} / \mathrm{H}-$ ZSM5. Zn cations provide a recombinative desorption pathway for the removal of $\mathrm{H}$-atoms, formed in $\mathrm{C}-\mathrm{H}$ bond activation steps during propane aromatization. ${ }^{3,20}$ As a result, the exchange of $\mathrm{Zn}$ cations onto $\mathrm{H}-\mathrm{ZSM} 5$ increases propane turnover rates and formation of aromatics and $\mathrm{H}_{2}$. In addition, $\mathrm{Zn}$ cations increase the selectivity to dehydrogenated products (propene and aromatics) and decrease the selectivity to hydrogen-rich methane and ethane products. ${ }^{2,3,20,25}$

Virtual Hydrogen Pressures During Propane Dehydrogenation on $\mathbf{H}-\mathbf{Z S M 5}$ and $\mathbf{Z n} / \mathbf{H}-\mathbf{Z S M 5}$. The appearance of D-atoms in the reaction products of $\mathrm{C}_{3} \mathrm{H}_{8} / \mathrm{D}_{2}$ mixtures on $\mathrm{H}-\mathrm{ZSM} 5$ and $\mathrm{Zn} / \mathrm{H}-\mathrm{ZSM} 5$ requires the dissociative adsorption of $\mathrm{D}_{2}$, which is the microscopic reverse of the recombinative desorption step required to complete a propane dehydrogenation turnover with removal of hydrogen as $\mathrm{H}_{2}$. All $\mathrm{C}_{2}+$ products of $\mathrm{C}_{3} \mathrm{H}_{8} / \mathrm{D}_{2}$ reactant mixtures showed similar deuterium contents (Figure 1) and binomial distributions of deuterated isotopomers (Figure 2) on $\mathrm{H}-\mathrm{ZSM} 5$. These findings suggest that extensive hydrogen redistribution occurs among a common pool of surface intermediates within the time required for a dehydrogenation or aromatization turnover. This isotopic scrambling occurs via rapid oligomerization-cracking cycles of intermediate alkene products, which lead to rapid intermolecular and intramolecular scrambling of carbon and hydrogen atoms among products and reaction intermediates formed from propane- $2-{ }^{13} \mathrm{C}$ reactants. ${ }^{2}$

The similar D-fraction measured for all $\mathrm{C}_{3}$ + products reflects the relative abundance of $\mathrm{D}$-atoms (from $\mathrm{D}_{2}$ ) and $\mathrm{H}$-atoms (from $\mathrm{C}_{3} \mathrm{H}_{8}$ ) within the pool of adsorbed species. If $\mathrm{H}$-desorption were irreversible during propane reactions, the surface and every reaction product formed at low propane conversions would contain only protium atoms. If hydrogen desorption were quasi- 


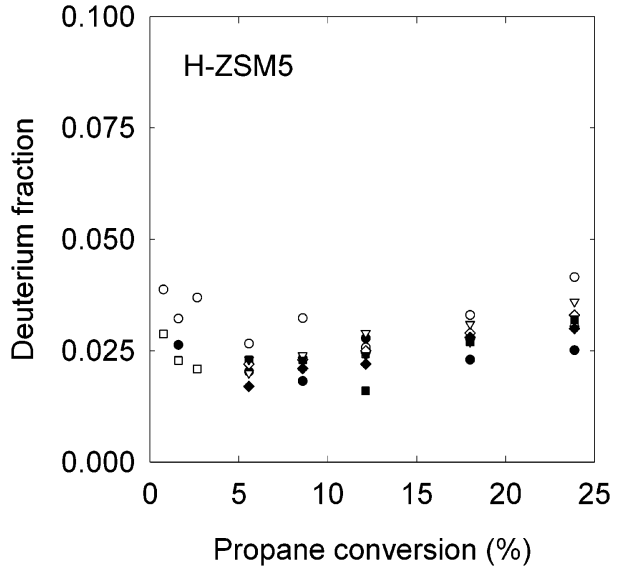

Figure 1. Deuterium fraction in propene, ethene, ethane, butene, butane, benzene, toluene, and xylene products of propane/deuterium mixtures on $\mathrm{H}-\mathrm{ZSM} 5\left(773 \mathrm{~K}, 26.6 \mathrm{kPa} \mathrm{C}_{3} \mathrm{H}_{8}, 6.7 \mathrm{kPa} \mathrm{D}, 68.0 \mathrm{kPa}\right.$ $\mathrm{He})$.

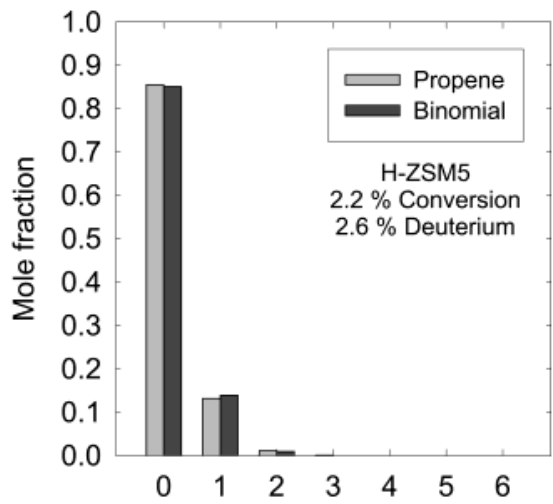

Number of deuteriums in propene

Figure 2. Deuterium distribution in propene product of propane/ deuterium mixtures on $\mathrm{H}-\mathrm{ZSM} 5\left(773 \mathrm{~K}, 26.6 \mathrm{kPa} \mathrm{C}{ }_{3} \mathrm{H}_{8}, 6.7 \mathrm{kPa} \mathrm{D}_{2}\right.$, $68.0 \mathrm{kPa} \mathrm{He}, 2.2 \%$ propane conversion).

TABLE 1: Hydrogen Virtual Pressures from Recirculating $\left(773 \mathrm{~K}, 26.6 \mathrm{kPa} \mathrm{C}_{3} \mathrm{H}_{8}, 6.7 \mathrm{kPa} \mathrm{D}_{2}\right)^{3}$ and Flow Reactors (773 $\mathrm{K}, 20 \mathrm{kPa} \mathrm{C} \mathrm{H}_{8}, 10 \mathrm{kPa} \mathrm{D}$ )

\begin{tabular}{|c|c|c|c|c|c|}
\hline \multirow[b]{2}{*}{ catal } & \multirow[b]{2}{*}{$\mathrm{Zn} / \mathrm{Al}$} & \multicolumn{2}{|c|}{ recirculating reactor } & \multicolumn{2}{|c|}{ flow reactor } \\
\hline & & $\left(H^{*} / D^{*}\right)$ & $\left(\mathrm{H}_{2}\right)_{\mathrm{v}} / \mathrm{kPa}$ & $\left(H^{*} / D^{*}\right)$ & $\left(\mathrm{H}_{2}\right)_{\mathrm{v}} / \mathrm{kPa}$ \\
\hline H-ZSM5 & 0.00 & 32.3 & 216 & & \\
\hline Zn/H-ZSM5 (0.62\%) & 0.10 & 6.7 & 45 & & \\
\hline Zn/H-ZSM5 (1.07\%) & 0.16 & 3.6 & 24 & 2.2 & 22 \\
\hline Zn/H-ZSM5 (1.30\%) & 0.19 & 2.0 & 14 & & \\
\hline
\end{tabular}

equilibrated, all products and adsorbed intermediates would contain only deuterium, at least at low conversions before $\mathrm{H}$-atoms are extracted from propane and introduced into the gas phase as $\mathrm{H}_{2}$ and $\mathrm{HD}$ molecules, because of rapid equilibration with the initially pure $\mathrm{D}_{2}$ gas phase. The D-content in products provides a measure of the relative abundance of $\mathrm{D}$ and $\mathrm{H}$ in the alkyl and alkenyl adsorbed species, of the virtual protium pressure in this surface pool, and of the extent to which hydrogen adsorption-desorption steps are reversible during steady-state propane conversion.

$\mathrm{The} \mathrm{H} / \mathrm{D}$ atomic ratios in the adsorbed intermediates involved in the formation of the observed products and the hydrogen virtual pressures, $\left(\mathrm{H}_{2}\right)_{\mathrm{v}}$, calculated from these data, are shown in Table 1. $\mathrm{H} / \mathrm{D}$ ratios were obtained from the average $\mathrm{D}$ content in all $\mathrm{C}_{3+}$ products formed from $\mathrm{C}_{3} \mathrm{H}_{8}-\mathrm{D}_{2}$ reactants on all samples, and $\left(\mathrm{H}_{2}\right)_{\mathrm{v}}$ was calculated using eq 10. Evidence for the use of this equation, which corresponds to the dissociation

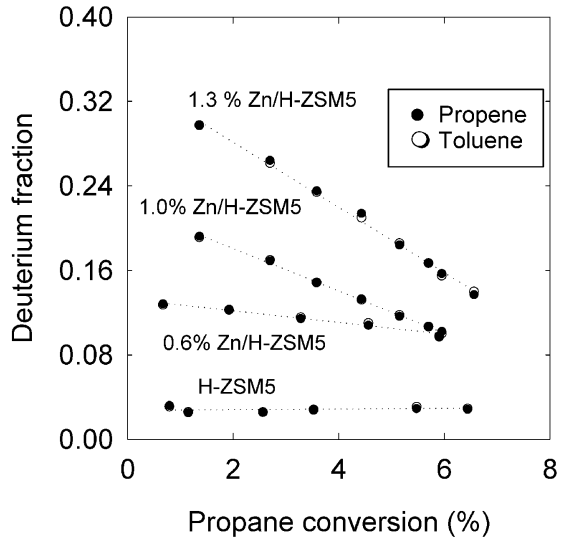

Figure 3. Deuterium fraction in toluene products of propane/deuterium mixtures on $\mathrm{H}-\mathrm{ZSM} 5$ and $1.07 \% \mathrm{Zn} / \mathrm{H}-\mathrm{ZSM} 5\left(773 \mathrm{~K}, 26.6 \mathrm{kPa} \mathrm{C}_{3} \mathrm{H}_{8}\right.$, $6.7 \mathrm{kPa} \mathrm{D}, 68.0 \mathrm{kPa} \mathrm{He}$ ).

of a $\mathrm{H}_{2}$ molecule that provides one mobile and one immobile $\mathrm{H}$-atom, is presented below.

Reaction products formed on $\mathrm{H}-\mathrm{ZSM} 5$ contain predominately protium $(\mathrm{H} / \mathrm{D}=32.3)$, and they appear to form from adsorbed intermediates containing mostly $\mathrm{H}$-atoms formed in $\mathrm{C}-\mathrm{H}$ activation steps. This reflects the facile activation of $\mathrm{C}-\mathrm{H}$ bonds on H-ZSM5 followed by slower kinetically relevant hydrogen removal steps, which remain far from quasi-equilibrium with $\mathrm{H}_{2}$ in the gas phase. Hydrogen desorption steps are nearly irreversible on $\mathrm{H}-\mathrm{ZSM} 5$, and the measured $\mathrm{H} / \mathrm{D}$ ratios correspond to a $\mathrm{H}_{2}$ virtual pressure of $216 \mathrm{kPa}$ (Table 1) at 773 $\mathrm{K}$ and $20 \mathrm{kPa}$ propane. The pool of reactive carbenium ions acts for all kinetic purposes as if it were in equilibrium with $216 \mathrm{kPa}$ of $\mathrm{H}_{2}$ in the gas phase, even though the actual $\mathrm{H}_{2}$ pressure during these steady-state $\mathrm{C}_{3} \mathrm{H}_{8}$ reactions on $\mathrm{H}-\mathrm{ZSM} 5$ at $773 \mathrm{~K}$ is less than $1 \mathrm{kPa}$.

The presence of $\mathrm{Zn}$ cations at exchange sites in $\mathrm{H}-\mathrm{ZSM} 5$ $(\mathrm{Zn} / \mathrm{Al}=0.10)$ increased the $\mathrm{D}$-content in all $\mathrm{C}_{3+}$ reaction products (Figure 3). The average H/D ratio (6.7) in reaction products and the virtual pressure at these catalytic surfaces (45 $\mathrm{kPa}$ ) are much lower than on $\mathrm{H}-\mathrm{ZSM} 5$ (Table 1). Zn cations catalyze the recombinative desorption of hydrogen adatoms and the dissociative adsorption of dihydrogen. ${ }^{3,20}$ As a result, the rate of communication between the surface and gas-phase hydrogen pools increases when $\mathrm{Zn}$ cations are present. Consistent with this, the D-content in all products increases with increasing $\mathrm{Zn}$ content, indicating that the density of D-atoms (from $\mathrm{D}_{2}$ ) relative to $\mathrm{H}$-atoms (from $\mathrm{C}_{3} \mathrm{H}_{8}$ ) in the pool of reactive intermediates increases as the efficiency or the number of desorption sites increase. Although $\mathrm{Zn}$ increases the reversibility of the hydrogen desorption step, this step does not reach quasiequilibrium even at the highest $\mathrm{Zn}$ content $(\mathrm{Zn} / \mathrm{Al}=0.19)$ and the surface pool of intermediates retains a significant number of the $\mathrm{H}$-atoms formed in $\mathrm{C}-\mathrm{H}$ bond activation steps. As a result, $\mathrm{Hz}$ virtual pressures remain higher than those in the prevalent gas phase (14 $\mathrm{kPa}$ vs $\sim 1-3 \mathrm{kPa}$ ) at all $\mathrm{Zn} / \mathrm{Al}$ ratios.

Effect of Gas-Phase $\mathrm{H}_{2}$ on Propane Dehydrogenation Rates and Selectivities on $\mathrm{H}-\mathrm{ZSM} 5$ and $\mathrm{Zn} / \mathrm{H}-\mathrm{ZSM} 5$. Propane reaction rates decreased slightly on H-ZSM5 and strongly on $\mathrm{Zn} / \mathrm{H}-\mathrm{ZSM} 5$ when $\mathrm{H}_{2}$ was introduced along with $\mathrm{C}_{3} \mathrm{H}_{8}$ reactants (Figure 4). The selectivity to hydrogen-rich products (e.g. $\mathrm{CH}_{4}$ and $\mathrm{C}_{2} \mathrm{H}_{6}$ ) increased and the selectivity to unsaturated products $\left(\mathrm{C}_{6+}\right.$ aromatics) decreased with increasing $\mathrm{H}_{2}$ partial pressure. These effects on selectivity were also much stronger on $\mathrm{Zn} / \mathrm{H}-\mathrm{ZSM} 5$ than on $\mathrm{H}-\mathrm{ZSM} 5$ (Figure 5). On both catalysts, propane conversion rates and aromatics selectivities 


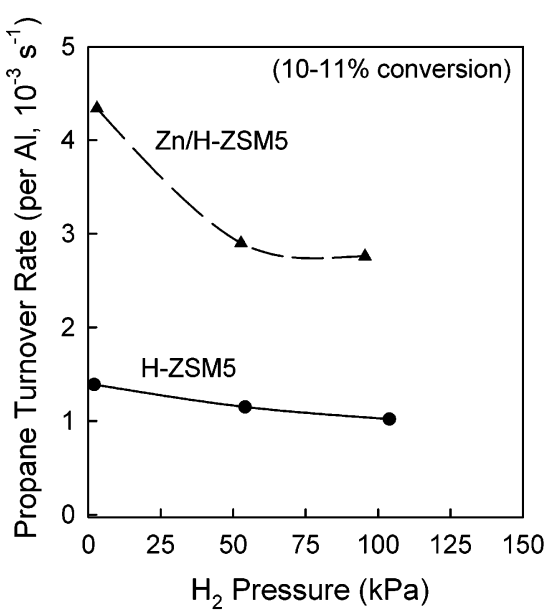

Figure 4. Inhibiting effect of added $\mathrm{H}_{2}$ on propane conversion rates on $\mathrm{H}-\mathrm{ZSM} 5$ (solid circles) and $\mathrm{Zn} / \mathrm{H}-\mathrm{ZSM} 5$ (solid triangles) (773 $\mathrm{K}, 20 \mathrm{kPa} \mathrm{C} \mathrm{H}_{8}, 0-100 \mathrm{kPa} \mathrm{H}, 10-11 \%$ propane conversion).

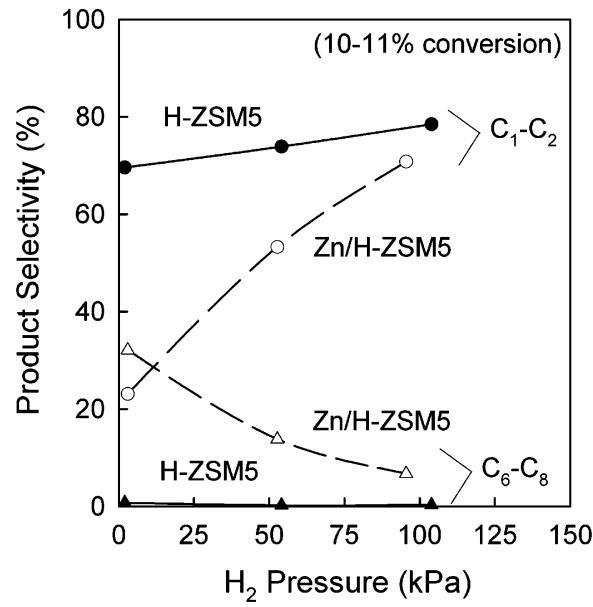

Figure 5. Effect of added $\mathrm{H}_{2}$ on product selectivities: $\mathrm{C}_{1-} \mathrm{C}_{2}$ (circles) and $\mathrm{C}_{6} \mathrm{C}_{8}$ (triangles) on $\mathrm{H}-\mathrm{ZSM} 5$ (solid symbols) and $\mathrm{Zn} / \mathrm{H}-\mathrm{ZSM} 5$ (open symbols) $\left(773 \mathrm{~K}, 20 \mathrm{kPa} \mathrm{C}_{3} \mathrm{H}_{8}, 0-100 \mathrm{kPa} \mathrm{H}_{2}, 10-11 \%\right.$ propane conversion).

decreased with increasing $\mathrm{H}_{2}$ partial pressure (Figures 4 and 5). $\mathrm{H}_{2}$ increased the selectivity to cracking products by increasing the hydrogen content in the surface alkyl and alkenyl carbenium ion intermediates, a process that is much more effective when $\mathrm{Zn}$ cations are available to dissociate $\mathrm{H}_{2}$. The same sites available to desorb $\mathrm{H}_{2}$ during propane aromatization are used when gas phase $\mathrm{H}_{2}$ is available in order to reintroduce hydrogen species onto the surface and to convert surface species into more hydrogen-rich reaction intermediates.

Hydrogen removal as $\mathrm{H}_{2}$ is nearly irreversible on $\mathrm{H}-\mathrm{ZSM} 5$; therefore, $\mathrm{H}_{2}$ influences propane conversion rates and selectivity weakly and only at high $\mathrm{H}_{2}$ pressures. On $\mathrm{H}-\mathrm{ZSM} 5$, surface intermediates are more saturated and they exist in quasiequilibrium with a virtual $\mathrm{H}_{2}$ pressure significantly higher than that in the prevalent gas phase; therefore, the effects of externally added $\mathrm{H}_{2}$ become visible only when the gas-phase pressure approaches the virtual pressures prevalent during dehydrogenation reactions of alkanes.

$\mathrm{Zn} / \mathrm{H}-\mathrm{ZSM} 5$ catalysts show much stronger $\mathrm{H}_{2}$ effects on rate and selectivity than $\mathrm{H}-\mathrm{ZSM} 5$, because $\mathrm{Zn}$ cations catalyze recombinative desorption steps and also their microscopic reverse - the dissociative chemisorption of $\mathrm{H}_{2}$-during propane reactions. $\mathrm{Zn}$ cations increase the rate of communication between $\mathrm{H}_{2}$ and propane-derived surface intermediates. As $\mathrm{H}_{2}$ pressures increase, $\mathrm{Zn} / \mathrm{H}-\mathrm{ZSM} 5$ approaches the catalytic behavior of

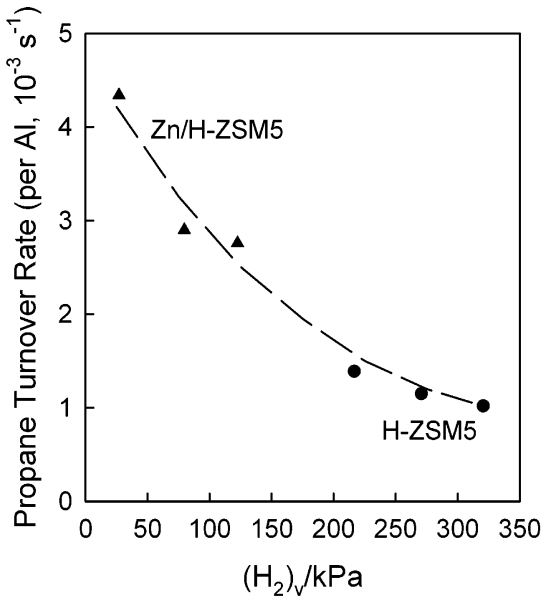

Figure 6. Hydrogen virtual pressure effect on propane reaction rate on $\mathrm{H}-\mathrm{ZSM} 5$ (solid circles) and $\mathrm{Zn} / \mathrm{H}-\mathrm{ZSM} 5$ (solid triangles) (773 $\mathrm{K}, 20 \mathrm{kPa} \mathrm{C} \mathrm{H}_{8}, 0-100 \mathrm{kPa} \mathrm{H}_{2}$ ).

$\mathrm{H}-\mathrm{ZSM} 5$, in terms of both propane conversion rate and selectivity reactions. The external source of $\mathrm{H}_{2}$ introduces hydrogen into the pool of alkyl and alkenyl intermediates on $\mathrm{Zn} / \mathrm{H}-\mathrm{ZSM}$, increasing their hydrogen content and causing their concentration and degree of saturation to approach those prevalent on hydrogen-rich $\mathrm{H}-\mathrm{ZSM} 5$ surfaces, where a high indigenous hydrogen chemical potential exists as a result of hydrogen removal bottlenecks operative during steady-state propane dehydrogenation reactions.

Hydrogen Virtual Pressures and Catalyst Rates, Selectivity, and Deactivation. The chemical potential of hydrogen in reactive intermediates and on catalytic surfaces depends on the gas-phase $\mathrm{H}_{2}$ concentration, on the rate of activation of propane, and on the rate of communication between propane-derived reaction intermediates and gas-phase $\mathrm{H}_{2}$ via adsorptiondesorption steps. When $\mathrm{H}_{2}$ is added, the hydrogen virtual pressure reflects the combined effects of the added $\mathrm{H}_{2}$ and of the virtual pressures prevalent during propane reactions. This approach assumes that the addition of gas-phase hydrogen does not affect the rate at which $\mathrm{C}-\mathrm{H}$ bonds are activated; the assumption is supported by previous findings showing that these steps are quasi-equilibrated during propane conversion on both $\mathrm{H}-\mathrm{ZSM} 5$ and $\mathrm{Zn} / \mathrm{H}-\mathrm{ZSM} 5$. $^{3}$

Figures 6-8 show that reaction rates, selectivities, and deactivation rates reflect these surface hydrogen virtual pressures, irrespective of the actual gas-phase $\mathrm{H}_{2}$ pressure or the catalyst composition. Reaction rates decreased with increasing $\left(\mathrm{H}_{2}\right)_{\mathrm{v}}$, because $\mathrm{H}$-atoms reverse $\mathrm{C}-\mathrm{H}$ bond activation steps, shift the equilibrium position of this quasi-equilibrated step, and lead to fewer or less reactive propane-derived reactive intermediates (Figure 6). As $\left(\mathrm{H}_{2}\right)_{\mathrm{v}}$ increased, whether by adding $\mathrm{H}_{2}$ to the reactant mixtures or by preventing the desorption of hydrogen species formed in $\mathrm{C}-\mathrm{H}$ bond activation, the selectivity to hydrogen-rich $C_{1}$ and $C_{2}$ products increased, while the selectivities to propene and to aromatics decreased (Figure 7). Hydrogenrich reaction intermediates tend to crack to form these hydrogenrich fragments, while unsaturated intermediates tend to desorb as alkenes and aromatics. Thus, reactive intermediates with a high hydrogen content lead predominantly to the re-formation of the alkane reactants, to the hydrogenation of alkenes, and to a decrease in the rate of formation of dehydrogenated products. These data suggest that the hydrogen chemical potential in the pool of surface carbocationic intermediates plays a critical role in controlling the level of unsaturation (e.g., alkyl vs alkenyl) in reaction intermediates and that $\mathrm{Zn}$ cations decrease the 


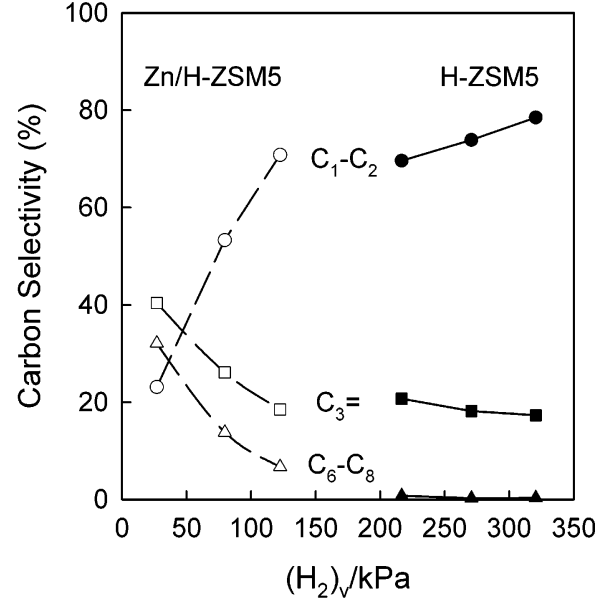

Figure 7. Hydrogen virtual pressure effect on product selectivity: $\mathrm{C}_{1-} \mathrm{C}_{2}$ (circles), propene (squares), and $\mathrm{C}_{6} \mathrm{C}_{8}$ (triangles) on $\mathrm{H}-\mathrm{ZSM} 5$ (solid symbols) and $\mathrm{Zn} / \mathrm{H}-\mathrm{ZSM} 5$ (open symbols) (773 K, $20 \mathrm{kPa} \mathrm{C}_{3} \mathrm{H}_{8}$, 0-100 $\mathrm{kPa} \mathrm{H}_{2}, 10-11 \%$ propane conversion).

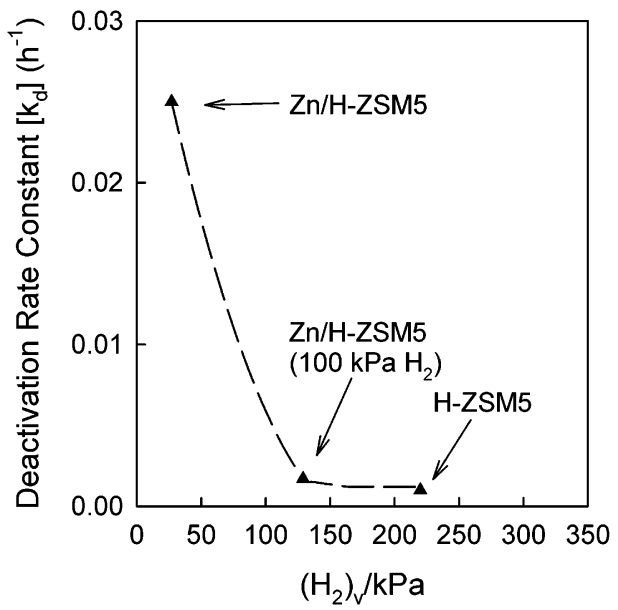

Figure 8. Hydrogen virtual pressure effect on deactivation rate on $\mathrm{H}-\mathrm{ZSM} 5$ and $\mathrm{Zn} / \mathrm{H}-\mathrm{ZSM} 5\left(1.07\right.$ wt $\% \mathrm{Zn}, 773 \mathrm{~K}, 20 \mathrm{kPa} \mathrm{C}_{3} \mathrm{H}_{8}, 0$ or $100 \mathrm{kPa} \mathrm{H}_{2}$, balance $\mathrm{He}$ ).

hydrogen content of these reactive intermediates adsorbed on acid sites in $\mathrm{H}-\mathrm{ZSM}$ 5.

Clearly, the degree of unsaturation in these reactive intermediates must also influence the frequency with which highly unsaturated unreactive species form during alkane reaction turnovers. Guisnet and Magnoux ${ }^{26}$ have proposed that the deactivation rates by carbon deposition during hydrocarbon reaction on zeolites depend on the surface concentration of highly unsaturated alkenyl and alkylaryl carbenium ions. The first-order deactivation rate constants $\left(k_{\mathrm{d}}\right)$ obtained from our time-on-stream rate data for propane reactions on $\mathrm{H}-\mathrm{ZSM} 5$ and $\mathrm{Zn} / \mathrm{H}-\mathrm{ZSM} 5$ showed that deactivation rates decreased with increasing $\left(\mathrm{H}_{2}\right)_{\mathrm{v}}$ (Figure 8), consistent with an increase in the average degree of saturation of reactive intermediates. The deactivation rates decrease with increasing hydrogen content irrespective of whether the hydrogen chemical potential at surfaces is varied by increasing the $\mathrm{H}_{2}$ pressure on $\mathrm{Zn} / \mathrm{H}-\mathrm{ZSM} 5$ or $\mathrm{H}-\mathrm{ZSM} 5$ or by avoiding desorption sites (Zn cations) during reactions of pure propane. On $\mathrm{H}-\mathrm{ZSM} 5$, high indigenous hydrogen virtual pressures decrease deactivation rates relative to those observed on $\mathrm{Zn} / \mathrm{H}-\mathrm{ZSM} 5$. On $\mathrm{Zn} / \mathrm{H}-\mathrm{ZSM}$, and to a lesser extent on $\mathrm{H}-\mathrm{ZSM} 5$, deactivation rates decrease with increasing gas-phase $\mathrm{H}_{2}$ pressures, as gas-phase $\mathrm{H}_{2}$ and reactive intermediates equilibrate via $\mathrm{Zn}$ cations. $\mathrm{Zn} / \mathrm{H}-\mathrm{ZSM} 5$ acquires the stability typical of $\mathrm{H}-\mathrm{ZSM} 5$ as $\mathrm{H}_{2}$ pressures increase and the catalytic surface acquires the high hydrogen chemical potentials prevalent during propane reactions on $\mathrm{H}-\mathrm{ZSM} 5 . \mathrm{Zn} /$ $\mathrm{H}-\mathrm{ZSM} 5$ also acquires, as shown above, the low aromatics selectivity and high cracking selectivities typical of H-ZSM5 as $\mathrm{H}_{2}$ pressures increase. Similar roles of cations and inhibition effects of $\mathrm{H}_{2}$ have been reported on $\mathrm{Ga} / \mathrm{H}-\mathrm{ZSM} 5$ catalysts. ${ }^{27}$

The effect of $\left(\mathrm{H}_{2}\right)_{\mathrm{v}}$ on reaction rates, selectivities, and deactivation rates shows that the surface behaves, for all kinetic purposes, as if it were in equilibrium with the prevalent virtual pressure $\left(\mathrm{H}_{2}\right)_{\mathrm{v}}$. The reaction rates, selectivities, and deactivation rates show consistent trends with virtual pressures calculated using eq 10 (Figures 6-8) but not with those calculated from calculated using eq 9. This provides indirect evidence for a specific mechanism for $\mathrm{H}$-desorption pathways, in which $\mathrm{H}_{2}$ dissociates providing one mobile $\mathrm{H}$-atom and one effectively fixed $\mathrm{H}$-atom, as expected from heterolytic cleavage of $\mathrm{H}_{2}$ molecules on isolated $\mathrm{Zn}-\mathrm{O}$ species and mobility of the $\mathrm{H}^{+\delta}$ species.

Hydrogen Virtual Pressures and Kinetic Coupling of $\mathbf{C}-\mathbf{H}$ Bond Activation with Reactions of Stoichiometric Hydrogen Acceptors. Hydrogen chemical potentials during alkane dehydrogenation reactions can be decreased by removing $\mathrm{H}$-atoms via kinetic coupling with a hydrogenation reaction. Stoichiometric acceptors of $\mathrm{H}$-atoms such as $\mathrm{O}_{2}, \mathrm{CO}$, and $\mathrm{CO}_{2}$ can be used to remove hydrogen and overcome the desorption bottleneck. ${ }^{27}$ The hydrogen content of the adsorbed surface intermediates can be influenced by the removal of $\mathrm{H}$-atoms through the coupling of the propane dehydrogenation reaction with hydrogenation reactions, such as thiophene desulfurization. ${ }^{22,28,29}$ These previous studies have shown that the presence of $20 \mathrm{kPa}$ of propane gives higher desulfurization rates than $200 \mathrm{kPa}$ of gas-phase $\mathrm{H}_{2}$ on $\mathrm{H}-\mathrm{ZSM} 5$ and equivalent rates to $50-100 \mathrm{kPa}$ of $\mathrm{H}_{2}$ on $\mathrm{Co} / \mathrm{H}-\mathrm{ZSM} 5$ and $\mathrm{Zn} / \mathrm{H}-\mathrm{ZSM} 5$. Similar roles of cations and inhibition effects of $\mathrm{H}_{2}$ have also been reported on $\mathrm{Ga} / \mathrm{H}-\mathrm{ZSM} 5$ catalysts. $\mathrm{H}$-atoms formed during $\mathrm{C}-\mathrm{H}$ activation steps can be more readily used than $\mathrm{H}$-atoms formed from $\mathrm{H}_{2}$ dissociation for the desulfurization of thiophene. Therefore, the high virtual pressures of hydrogen, caused by nonequilibrated $\mathrm{H}_{2}$ desorption steps, allows the use of alkanes as an alternate source of hydrogen in thiophene desulfurization reactions, while the hydrogen removal pathway introduced by this reaction increases the rate and selectivity of alkane dehydrogenation reactions.

\section{Conclusions}

The virtual hydrogen pressure provides a measurable surrogate for the hydrogen chemical potential in the pool of reactive intermediates involved in alkane reactions. This chemical potential provides the kinetic driving force for all chemical reactions of these intermediates, including those dehydrogenation reactions that render them unreactive and lead to irreversible titration of active sites by unreactive carbonaceous deposits. The presence of $\mathrm{H}_{2}$ during propane reactions on $\mathrm{Zn} / \mathrm{H}-\mathrm{ZSM} 5$ causes its surface to resemble that of $\mathrm{H}-\mathrm{ZSM} 5$ in reaction rate, selectivity, and deactivation rate. In the process, $\mathrm{Zn} / \mathrm{H}-\mathrm{ZSM} 5$ kinetically resembles $\mathrm{H}-\mathrm{ZSM} 5$ at $\mathrm{H}_{2}$ pressures similar to the virtual pressures prevalent during propane reactions on $\mathrm{H}-\mathrm{ZSM}$ 5. Hydrogen concentrations and chemical potentials on these catalytic surfaces reflect the rates at which hydrogen is formed in $\mathrm{C}-\mathrm{H}$ bond activation steps and in dissociative adsorption of gas-phase $\mathrm{H}_{2}$. The kinetic behavior of the hydrogen species formed from these two sources appears to be indistinguishable. 
Both sources place hydrogen atoms within a pool of reactive intermediates, the hydrogen content of which controls the rate and selectivity of all surface-catalyzed chemical reactions.

Acknowledgment. This work was supported by the National Science Foundation (Grant CTS-99-85701).

\section{References and Notes} 549 .

(1) Iglesia, E.; Baumgartner, J. E.; Price, G. L. J. Catal. 1992, 134,

(2) Biscardi, J. A.; Iglesia, E. Catal. Today 1996, 31, 207.

(3) Biscardi, J. A.; Iglesia, E. J. Catal. 1999, 182, 117.

(4) Li, W.; Biscardi, J. A.; Yu, S. Y.; Iglesia, E. Phys. Chem. Chem. Phys., submitted for publication.

(5) Yu, S. Y.; Yu, G. J.; Li, W.; Iglesia, E. J. Phys. Chem. B 2002, 106, 4714.

(6) Dahl, I. M.; Kolboe, S. Catal. Lett. 1993, 20, 329.

(7) Dahl, I. M.; Kolboe, S. J. Catal. 1994, 149, 458.

(8) Guisnet, M.; Gnep, N. S.; Alario, F. Appl. Catal. 1992, 89, 1

(9) Iglesia, E.; Wang, T.; Yu, S. Y. Stud. Surface Sci. Catal. 1998, $119,527$.

(10) Kazansky, V. B.; Senchenya, I. N. J. Catal. 1989, 119, 108.

(11) Kazansky, V. B.; Senchenya, I. N. J. Mol. Catal. 1992, 74, 257.
(12) Kiricsi, I.; Forster, H.; Tasi, G.; Nagy, J. B. Chem. Rev. 1999, 99, 2085

(13) Boudart, M. J. Phys. Chem. 1983, 87, 2786.

(14) Boudart, M. Ind. Eng. Chem. Fundam. 1986, 25, 70

(15) Boudart, M. Catal. Lett. 1989, 3, 111.

(16) De Donder, T. L'Affinite; Gauthier-Villars: Paris, 1927.

(17) Kemball, C. Discuss. Faraday Soc. 1966, 41, 190.

(18) Krylov, O. V. Kinet. Katal. 1995, 36, 39.

(19) Shindo, H.; Egawa, C.; Onishi, T.; Tamaru, K. J. Chem. Soc., FaradayTrans. 1 1980, 76, 280.

(20) Biscardi, J. A.; Meitzner, G. D.; Iglesia, E. J. Catal. 1998, 179 , 192.

(21) Li, W.; Yu, S. Y.; Meitzner, G. D.; Iglesia, E. J. Phys. Chem. B 2001, 105, 1176.

(22) Yu, S. Y.; Li, W.; Iglesia, E. J. Catal. 1999, 187, 257.

(23) Borry, R. W.; Kim, Y. H.; Huffsmith, A.; Reimer, J. A.; Iglesia, E. J. Phys. Chem. B 1999, 103, 5787.

(24) Price, G. L.; Iglesia, E. Ind. Eng. Chem. Res. 1989, 28, 839.

(25) Mole, T.; Anderson, J. R.; Creer, G. Appl. Catal. 1985, 17, 141.

(26) Guisnet, M.; Magnoux, P. Appl. Catal. 1989, 54, 1.

(27) Iglesia, E.; Baumgartner, J. E. Catal. Lett. 1993, 21, 55.

(28) Li, W.; Yu, S. Y.; Iglesia, E. Stud. Surf. Sci. Catal. 2000, 130, 899.

(29) Li, W.; Yu, S. Y.; Iglesia, E. J. Catal. 2001, 203, 175. 